\title{
Evaluation of the inhibitory effect of ivermectin on the growth of Babesia and Theileria parasites in vitro and in vivo
}

Gaber El-Saber Batiha ${ }^{1,2 \dagger}$, Amani Magdy Beshbishy ${ }^{1 \dagger}$, Dickson Stuart Tayebwa ${ }^{1,3}$, Oluyomi Stephen Adeyemi ${ }^{4}$, Naoaki Yokoyama ${ }^{1}$ and Ikuo Igarashi ${ }^{* *}$

\begin{abstract}
Background: Treatment is the principle way to control and eliminate piroplasmosis. The search for new chemotherapy against Babesia and Theileria has become increasingly urgent due to parasite resistance to current drugs. Ivermectin (IVM) was the world's first endectocide, capable of killing a wide variety of parasites and vectors, both inside and outside the body. It is currently authorized to treat onchocerciasis, lymphatic filariasis, strongyloidiasis, and scabies. The current study documented the efficacy of IVM on the growth of Babesia and Theileria in vitro and in vivo.

Methods: The fluorescence-based assay was used for evaluating the inhibitory effect of IVM on four Babesia species, including B. bovis, B. bigemina, B. divergens, B. caballi, and Theileria equi, the combination with diminazene aceturate $(\mathrm{DA})$, clofazimine $(\mathrm{CF})$, and atovaquone $(\mathrm{AQ})$ on in vitro cultures, and on the multiplication of a $B$. microtiinfected mouse model. The cytotoxicity of compounds was tested on Madin-Darby bovine kidney (MDBK), mouse embryonic fibroblast (NIH/3 T3), and human foreskin fibroblast (HFF) cell lines.

Results: The half-maximal inhibitory concentration $\left(\mathrm{IC}_{50}\right)$ values determined for IVM against $B$. bovis, B. bigemina, $B$. divergens, $B$. caballi, and T. equi were $53.3 \pm 4.8,98.6 \pm 5.7,30.1 \pm 2.2,43.7 \pm 3.7$, and $90.1 \pm 8.1 \mu \mathrm{M}$, respectively. Toxicity assays on MDBK, NIH/3 T3, and HFF cell lines showed that IVM affected the viability of cells with a half-maximal effective concentration ( $\mathrm{EC}_{50}$ ) of $138.9 \pm 4.9,283.8 \pm 3.6$, and $287.5 \pm 7.6 \mu \mathrm{M}$, respectively. In the in vivo experiment, IVM, when administered intraperitoneally at $4 \mathrm{mg} / \mathrm{kg}$, significantly $(p<0.05)$ inhibited the growth of $B$. microti in mice by $63 \%$. Furthermore, combination therapies of IVM-DA, IVM-AQ, and IVM-CF at a half dose reduced the peak parasitemia of $B$. microti by $83.7 \%, 76.5 \%$, and $74.4 \%$, respectively. Moreover, this study confirmed the absence of $B$. microti DNA in groups treated with combination chemotherapy of IVM + DA and IVM + AQ 49 days after infection.
\end{abstract}

Conclusions: These findings suggest that IVM has the potential to be an alternative remedy for treating piroplasmosis.

Keywords: Ivermectin, Babesia, Theileria, In vitro, In vivo

\section{Background}

Babesiosis is a malaria-like parasitic disease caused by Babesia, a genus of Apicomplexa [1]. Babesia bovis, B. bigemina, and $B$. divergens infect cattle, causing bovine babesiosis. In Europe, bovine babesiosis, known as red

\footnotetext{
* Correspondence: igarcpmi@obihiro.ac.jp

${ }^{\dagger}$ Gaber El-Saber Batiha and Amani Magdy Beshbishy contributed equally to this work.

${ }^{1}$ National Research Center for Protozoan Diseases, Obihiro University of Agriculture and Veterinary Medicine, Nishi 2 Sen-13, Inada-cho, Obihiro, Hokkaido 080-8555, Japan

Full list of author information is available at the end of the article
}

water fever, is mainly caused by $B$. divergens and is considered the most important tick-transmitted disease in cattle [2], while B. caballi and Theileria equi infect horses causing equine piroplasmosis [3]. Human babesiosis is uncommon; however, it is important as an emerging disease in the Northeastern and Midwestern United States and parts of Europe, and sporadic throughout the rest of the world [4]. The spectrum of human babesiosis is broad, ranging from an apparently silent infection to a fulminant, malaria-like disease resulting occasionally in death [5]. 
Treatment of babesiosis and theileriosis in animals depends on two common drugs, namely diminazene aceturate (DA) and imidocarb dipropionate, while human babesiosis has been managed with a combination of atovaquone (AQ) and azithromycin and a combination of clindamycin and quinine [6]. Recently, González et al. showed the failure, ineffectiveness, adverse reaction, and relapsing babesiosis of clindamycin and quinine combination treatment in splenectomized patients infected by $B$. divergens or B. microti [7], while Hatcher et al. showed that patients affected by severe babesiosis had adverse reactions to quinine treatment and persistently high parasitemia more than 10 days after treatment with a combination of AQ and azithromycin [8]. In addition, Babesia gibsoni has been shown to be resistant to AQ [9]. Therefore, research to find new drugs and drug targets is the fundamental approach for addressing current limitations.

Ivermectin (IVM) is a macrocyclic lactone derived from avermectin, which is produced by an actinomycete, Streptomyces avermitilis [10]. IVM is a safe drug active against a wide range of internal and external parasites, and it is used widely in both veterinary and human medicine $[11,12]$. In human medicine, IVM is used to treat onchocerciasis (river blindness). IVM is effective against many worm infestations (such as strongyloidiasis, ascariasis, trichuriasis, filariasis, and enterobiasis) and some epidermal parasitic skin diseases, including scabies [13]. Originally thought to have antibacterial or antiviral properties, IVM has recently been reported to kill $\mathrm{Myco}$ bacterium tuberculosis, including multidrug-resistant strains [14]. IVM induces chloride-dependent membrane hyperpolarization and cell death in leukemia cells, prompting suggestions that it could be rapidly put into clinical trials for leukemia. IVM was shown to be a highly potent inhibitor of yellow fever virus replication and the replication of several other flaviviruses, notably dengue, Japanese encephalitis, and tick-borne encephalitis [14]. Recently, the endectocide IVM has arisen as a promising new tool to be added to malaria control programs [12]. Moreover, new possible uses are continuing to emerge, heralding potential breakthroughs in tackling various neglected tropical diseases-and beyond. Research has shown that, for human African trypanosomiasis (sleeping sickness), deworming cattle with single doses of IVM decrease the survival and fecundity of disease-transmitting tsetse flies feeding on cattle by up to $94 \%$ [15]. IVM is also efficacious in curing cutaneous leishmaniasis, killing Leishmania parasites in vitro and via subcutaneous inoculation [16].

In veterinary medicine, IVM is used against many intestinal worms, most mites, and some lice. It is sometimes administered in combination with other medications to treat a broad spectrum of animal parasites [10]. In addition, IVM can be given by mouth, topically, or via injection. As a drug targeting nematode and arthropod parasites, IVM has not been reported to directly interact with any mammalian proteins with high selectivity [17]. In this study, we evaluated the effects of IVM against the growth of B. bigemina, B. bovis, B. divergens, B. caballi, and $T$. equi in vitro as well as the chemotherapeutic potential of IVM on $B$. microti in vivo.

\section{Results \\ The growth inhibitory effect of IVM against Babesia and Theileria}

Growth inhibitory assays were conducted on five species: B. bovis, B. bigemina, B. divergens, B. caballi, and $T$. equi. IVM inhibited the multiplication and growth of all species tested in a dose-dependent manner (Figs. 1 and $2)$. The half-maximal inhibitory concentration $\left(\mathrm{IC}_{50}\right)$ values of IVM on $B$. bovis, B. bigemina, B. divergens, $B$. caballi, and $T$. equi were $53.3 \pm 4.8,98.6 \pm 5.7,30.1 \pm 2.2$, $43.7 \pm 3.7$, and $90.1 \pm 8.1 \mu \mathrm{M}$, respectively (Table 1 ). In this study, diminazene aceturate (DA) showed $\mathrm{IC}_{50}$ values at $0.35,0.68,0.43,0.022$, and $0.71 \mu \mathrm{M}$ against $B$. bovis, B. bigemina, B. divergens, B. caballi, and T. equi, respectively. Atovaquone (AQ) showed $\mathrm{IC}_{50}$ values at $0.039,0.701,0.038,0.102$, and $0.095 \mu \mathrm{M}$ against B. bovis, $B$. bigemina, $B$. divergens, $B$. caballi, and T. equi, respectively. Clofazimine (CF) showed $\mathrm{IC}_{50}$ values at 8.24, $5.73,13.85,7.95$, and $2.88 \mu \mathrm{M}$ against B. bovis, B. bigemina, $B$. divergens, $B$. caballi, and $T$. equi, respectively (Additional file 3: Table S3). The effectiveness of IVM was not influenced by the diluent since there was no significant difference in the inhibition between wells containing DMSO and untreated wells. The precultivation of RBCs with IVM was conducted to determine its direct effect on host RBCs. Bovine and equine RBCs were incubated with IVM at 10, 100, and $200 \mu \mathrm{M}$ for 3 and $6 \mathrm{~h}$ to be used for the parasite subculture. The multiplication of all parasites did not significantly differ between IVM-treated RBCs and normal RBCs for either species (data not shown).

\section{Toxicity of IVM, DA, AQ, and CF on MDBK, NIH/3 T3, and HFF cell lines}

IVM showed an inhibitory effect on the in vitro culture of Babesia and Theileria parasites. Therefore, the effect of IVM on host cells was evaluated using Madin-Darby bovine kidney (MDBK), NIH/3 T3, and human foreskin fibroblast (HFF) cell lines to see the cytotoxicity of the IVM compound (Table 1). The half-maximal effective concentration $\left(\mathrm{EC}_{50}\right)$ values of IVM on MDBK, NIH/3 T3, and HFF cell lines were 138.9 $\pm 4.9,283.8 \pm 3.6$, and $287.5 \pm 7.6 \mu \mathrm{M}$, respectively. The selectivity indexes are defined as the ratio of cell line $\mathrm{EC}_{50}$ to the parasite $\mathrm{IC}_{50}$. The highest selectivity index was achieved on $B$. divergens; as in the case of the MDBK cell line, it was found 


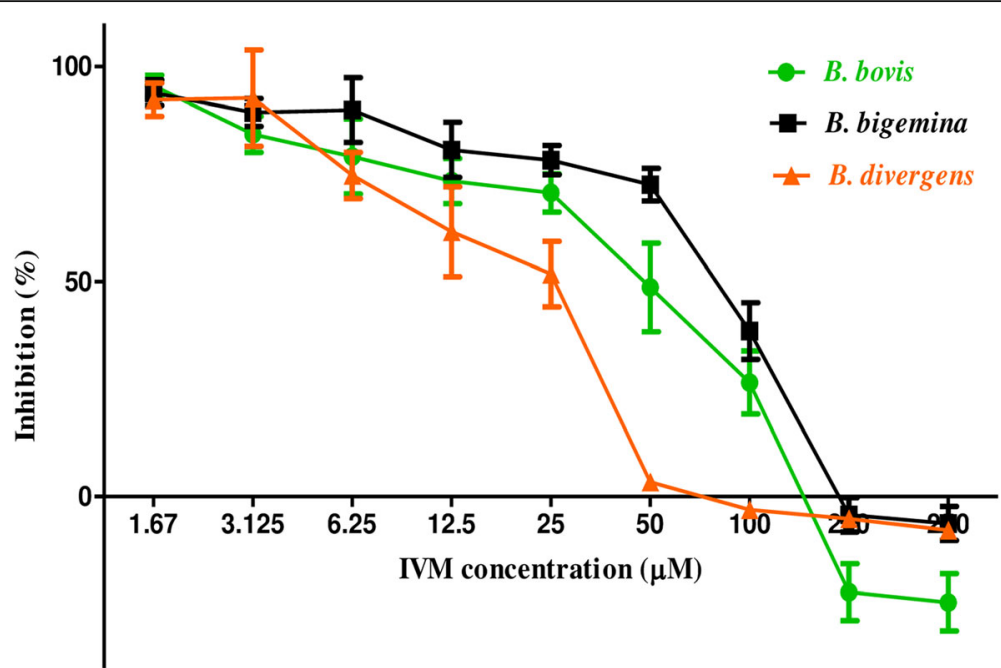

Fig. 1 The dose-response curves of ivermectin against bovine Babesia parasites in vitro. The curve shows the correlation between relative fluorescence units (RFUs) and the log concentrations of IVM $(\mu M)$ in B. bovis, B. bigemina, and B. divergens treated with various concentrations of IVM. The result was determined by fluorescence assay after $96 \mathrm{~h}$ of incubation. The values obtained from three separate trials were used to determine the $\mathrm{IC}_{50} \mathrm{~S}$ using nonlinear regression (curve fitting analysis) in GraphPadPrism software

to be 4.6 times higher than the $\mathrm{IC}_{50}$; while in case of the $\mathrm{NIH} / 3 \mathrm{~T} 3$ cell line, it was found to be 9.4 times higher than the $\mathrm{IC}_{50}$; and in case of the HFF cell line, it was found to be 9.6 times higher than the $\mathrm{IC}_{50}$ (Table 1). In a separate assay, DA and $\mathrm{AQ}$ at concentrations of $100 \mu \mathrm{M}$ did not show any inhibition of MDBK, NIH/3 T3, and HFF cell viability, while CF showed inhibition only on MDBK with an $\mathrm{EC}_{50}$ value at $34 \pm 3.4 \mu \mathrm{M}$ (Additional file 3: Table S3). The highest selectivity index of DA was achieved on B. caballi, while for AQ and $\mathrm{CF}$ the highest selectivity index was achieved against
$B$. divergens and $T$. equi, respectively (Additional file 3: Table S3).

\section{The viability of parasites treated with IVM}

A viability assay was performed to determine whether the concentrations of IVM could completely clear parasites after 4 days of successive treatment, followed by withdrawal of the drug pressure. B. bovis, B. bigemina, $B$. divergens, and $B$. caballi treated with IVM could not regrow at the concentration of $4 \times \mathrm{IC}_{50}$, while $T$. equi could regrow at the concentration of $4 \times \mathrm{IC}_{50}$ (Table 2).

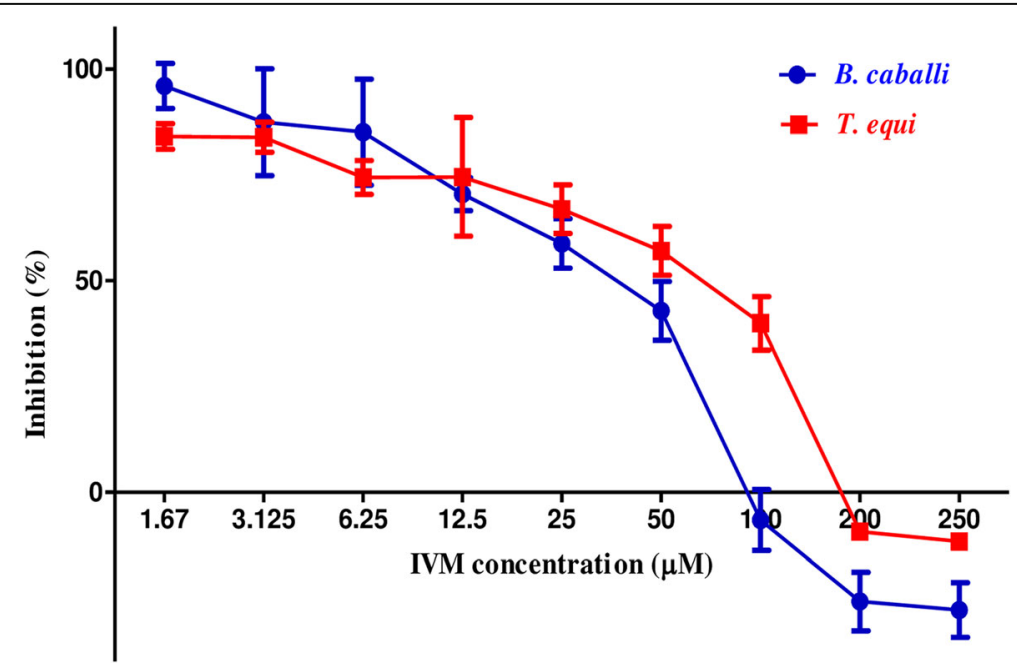

Fig. 2 The dose-response curves of ivermectin against equine piroplasm parasites in vitro. The curve shows the correlation between relative fluorescence units (RFUs) and the log concentrations of IVM ( $\mu \mathrm{M})$ in B. caballi and T. equi treated with various concentrations of IVM. The result was determined by fluorescence assay after $96 \mathrm{~h}$ of incubation. The values obtained from three separate trials were used to determine the $\mathrm{C}_{50} \mathrm{~S}$ using nonlinear regression (curve fitting analysis) in GraphPadPrism software 
Table $1 \mathrm{IC}_{50}$ and selectivity index of IVM

\begin{tabular}{|c|c|c|c|c|c|c|c|c|}
\hline \multirow[t]{2}{*}{ Compound } & \multirow{2}{*}{$\begin{array}{l}\text { Babesia } \\
\text { and } \\
\text { Theileria }\end{array}$} & \multirow{2}{*}{$\begin{array}{l}I_{50} \\
(\mu \mathrm{M})^{\mathrm{a}}\end{array}$} & \multicolumn{3}{|l|}{$\mathrm{EC}_{50}(\mu \mathrm{M})^{\mathrm{b}}$} & \multicolumn{3}{|c|}{ Selective indices $^{c}$} \\
\hline & & & MDBK & $\mathrm{NIH} / 3 \mathrm{T3}$ & HFF & MDBK & $\mathrm{NIH} / 3 \mathrm{T3}$ & $\mathrm{HFF}$ \\
\hline \multirow[t]{5}{*}{ IVM } & B. bovis & $53.3 \pm 4.8$ & $138.9 \pm 4.9$ & $283.8 \pm 3.6$ & $287.5 \pm 7.6$ & 2.6 & 5.3 & 5.4 \\
\hline & B. bigemina & $98.6 \pm 5.7$ & $138.9 \pm 4.9$ & $283.8 \pm 3.6$ & $287.5 \pm 7.6$ & 1.4 & 2.9 & 2.9 \\
\hline & B. divergens & $30.1 \pm 2.2$ & $138.9 \pm 4.9$ & $283.8 \pm 3.6$ & $287.5 \pm 7.6$ & 4.6 & 9.4 & 9.6 \\
\hline & B. caballi & $43.7 \pm 3.7$ & $138.9 \pm 4.9$ & $283.8 \pm 3.6$ & $287.5 \pm 7.6$ & 3.2 & 6.5 & 6.6 \\
\hline & T. equi & $90.1 \pm 8.1$ & $138.9 \pm 4.9$ & $283.8 \pm 3.6$ & $287.5 \pm 7.6$ & 1.5 & 3.1 & 3.2 \\
\hline
\end{tabular}

${ }^{a}$ Half-maximal inhibition concentration of ivermectin on the in vitro culture of parasites. The value was determined from the dose-response curve using nonlinear regression (curve fit analysis). The values are the means of triplicate experiments

${ }^{\mathrm{b}}$ Half-maximal effective concentration of ivermectin on cell lines. The values were determined from the dose-response curve using nonlinear regression (curve fit analysis). The values are the means of triplicate experiments

${ }^{c}$ Ratio of the $\mathrm{EC}_{50}$ of cell lines to the $\mathrm{IC}_{50}$ of each species. High numbers are favorable

IVM ivermectin, MDBK Madin-Darby bovine kidney, NIH/3 T3 Mouse embryonic fibroblast, HFF Human foreskin fibroblast

\section{The effects of the combination of IVM with $D A, A Q$, and $\mathrm{CF}$ in vitro}

The drug combination assay was performed to examine whether the combined treatments are synergism (give a greater effect), additive (similar effect), or antagonism (reduce or block the effect). Five selected concentrations of IVM, as recommended in the Chou-Talalay method [18], were combined with $\mathrm{DA}, \mathrm{AQ}$, and $\mathrm{CF}$ at a constant ratio of (1:1). The percentage of inhibition of the single drug and each combination was analyzed using CompuSyn software to generate the combination index $(\mathrm{CI})$ value at $\mathrm{IC}_{50}, \mathrm{IC}_{75}$, $\mathrm{IC}_{90}$, and $\mathrm{IC}_{95}$ (Additional file 2: Table S2). The drug combination effect was considered synergetic if the value was less than 0.90, additive if the value was at a range of 0.90 1.10, and antagonistic if the value was more than 1.10. The effects of combination treatment of IVM-DA, IVM-AQ, and IVM-CF against $B$. bovis, B. bigemina, $B$. divergens, $B$. caballi, and T. equi are shown in Table 3. The combination treatments of IVM-DA showed synergistic effects against $B$. bigemina, B. divergens, and B. caballi, and an additive effect against $B$. bovis and T. equi. The combination treatments of IVM-AQ showed a synergistic effect against $B$. bigemina but an additive effect against $B$. bovis, $B$. divergens, $B$. caballi, and T. equi. Combination treatments of IVM-CF showed additive effects against $B$. bovis, B. bigemina, $B$. divergens, B. caballi, and T. equi, while none of the combinations showed an antagonistic effect.
The chemotherapeutic effect of IVM against $B$. microti

For further evaluation of IVM efficacy as compared with other drugs, the chemotherapeutic effect of IVM was examined in mice infected with $B$. microti (Fig. 3). In the DDW control group, the multiplication of $B$. microti increased significantly, reaching the highest parasitemia at $58.2 \%$ on day 8 post-infection (p.i). In all treated groups, the level of parasitemia was cleared at a significantly lower percentage of parasitemia than the control group $(p<0.05)$ from day's 6 to 12 p.i. In mono-chemotherapytreated mice, the peak parasitemia level reached $21.5 \%$, $3.9 \%$, and $4.3 \%$ on day 8 and $4.9 \%$ on day 7 in $4 \mathrm{mg} / \mathrm{kg}$ IVM, $25 \mathrm{mg} / \mathrm{kg} \mathrm{DA}, 20 \mathrm{mg} / \mathrm{kg} \mathrm{AQ}$, and $20 \mathrm{mg} / \mathrm{kg} \mathrm{CF}$, respectively (Fig. 3 ). The parasitemia was undetectable in mice treated with $25 \mathrm{mg} / \mathrm{kg} \mathrm{DA}, 20 \mathrm{mg} / \mathrm{kg} \mathrm{AQ}$, and $20 \mathrm{mg} / \mathrm{kg}$ CF via microscopy starting on day 13, 15, and 16 p.i., respectively. The parasitemia was undetectable by microscopy examination in mice treated with $4 \mathrm{mg} / \mathrm{kg}$ of IVM on day 30 p.i., while in the combination chemotherapy-treated groups, peak parasitemia levels reached $9.5 \%$, $15 \%$, and $14 \%$ in $2 \mathrm{mg} / \mathrm{kg}$ IVM- $12.5 \mathrm{mg} / \mathrm{kg}$ DA on day 8 , $2 \mathrm{mg} / \mathrm{kg}$ IVM-10 mg/kg CF on day 7, and $2 \mathrm{mg} / \mathrm{kg}$ IVM$10 \mathrm{mg} / \mathrm{kg}$ AQ on day 8, respectively (Fig. 4). Parasitemia was undetectable by microscopic examination in mice on days 13, 22, and 18 p.i. with $2 \mathrm{mg} / \mathrm{kg}$ IVM-12.5 mg/kg DA, $2 \mathrm{mg} / \mathrm{kg}$ IVM-10 mg/kg CF, and $2 \mathrm{mg} / \mathrm{kg}$ IVM-10 mg/kg $\mathrm{AQ}$, respectively. Infection with $B$. microti reduced the

Table 2 The viability of Babesia and Theileria parasites treated with IVM

\begin{tabular}{|c|c|c|c|c|c|c|}
\hline \multirow[t]{2}{*}{ Drugs } & \multirow{2}{*}{$\begin{array}{l}\text { Conc. of } \\
\text { compounds }\end{array}$} & \multicolumn{5}{|l|}{ Parasites } \\
\hline & & B. bovis & B. bigemina & B. divergens & B. caballi & T. equi \\
\hline \multirow[t]{6}{*}{ IVM } & $0.25 \times I C_{50}$ & + & + & + & + & + \\
\hline & $0.5 \times I C_{50}$ & + & + & + & + & + \\
\hline & $1 \times \mathrm{IC}_{50}$ & + & + & + & + & + \\
\hline & $2 \times 1 C_{50}$ & + & + & + & + & + \\
\hline & $4 \times I_{50}$ & - & - & - & - & + \\
\hline & Untreated control & + & + & + & + & + \\
\hline
\end{tabular}

The positive (+) shows the regrowth of parasites, and the negative (-) shows the total clearance of parasites on day 8 after withdrawing the drug pressure 
Table 3 The effect of ivermectin with diminazene aceturate, atovaquone, and clofazimine against Babesia and Theileria parasites in vitro

\begin{tabular}{|c|c|c|c|c|c|c|}
\hline \multirow{2}{*}{$\begin{array}{l}\text { Drug } \\
\text { combinations }\end{array}$} & & \multicolumn{5}{|l|}{ Parasites } \\
\hline & & B. bovis & B. bigemina & B. divergens & B. caballi & T. equi \\
\hline \multirow[t]{2}{*}{$\mathrm{IVM}+\mathrm{DA}$} & $\mathrm{Cl}$ values & 1.11051 & 0.40539 & 0.01779 & 0.14328 & 1.10124 \\
\hline & Degree of association & Additive & Synergistic & Synergistic & Synergistic & Additive \\
\hline \multirow[t]{2}{*}{$\mathrm{IVM}+\mathrm{AQ}$} & $\mathrm{Cl}$ values & 1.04737 & 0.82283 & 1.04901 & 1.07398 & 1.05367 \\
\hline & Degree of association & Additive & Synergistic & Additive & Additive & Additive \\
\hline \multirow[t]{2}{*}{$\mathrm{IVM}+\mathrm{CF}$} & $\mathrm{Cl}$ values & 0.92317 & 1.01390 & 1.01372 & 1.10847 & 0.99644 \\
\hline & Degree of association & Additive & Additive & Additive & Additive & Additive \\
\hline
\end{tabular}

$\mathrm{Cl}$ combination index, $A Q$ atovaquone, $C F$ clofazimine, $D A$ diminazene aceturate

hematocrit (HCT) count, hemoglobin (HGB) percentage, and red blood cell (RBC) count in mouse blood, as observed in the DDW control group on days $8,12,16$, and 20 p.i. Significantly higher differences $(p<0.05)$ in HCT count, HGB percentage, and RBC count were observed between the DDW control group and all drug-treated groups on days 8, 12, 16, and 20 (Fig. 5a-c). Furthermore, parasite DNA was not detected in $25 \mathrm{mg} / \mathrm{kg}$ DA-IP, $2 \mathrm{mg} / \mathrm{kg}$ IVM-12.5 mg/kg DA, or $2 \mathrm{mg} / \mathrm{kg}$ IVM-10 mg/kg AQ on day 49. Meanwhile, in all other groups-20 mg/kg AQ-oral, $20 \mathrm{mg} / \mathrm{kg} \mathrm{CF-oral,}$ $4 \mathrm{mg} / \mathrm{kg}$ IVM-IP, and $2 \mathrm{mg} / \mathrm{kg}$ IVM-10 mg/kg CF-parasite DNA was detected until day 49 (Fig. 6).

\section{Discussion}

Although several reports documented the efficacy of IVM in the tick control programs to prevent the tick transmission of several Babesia and Theileria species to cattle and dogs [19, 20], this is the first study to evaluate the efficacy of IVM as an antiparasitic agent against $\mathrm{Ba}$ besia and Theileria parasites in vitro and in vivo. In the current study, IVM inhibited the growth of B. bovis, $B$. bigemina, $B$. divergens, B. caballi, and T. equi in vitro. However, IVM showed slightly high $\mathrm{IC}_{50}$ values; they are still lower than those of $\mathrm{N}$-acetyl L-cysteine [21], allicin [22], and clodinafop-propargyl against bovine Babesia

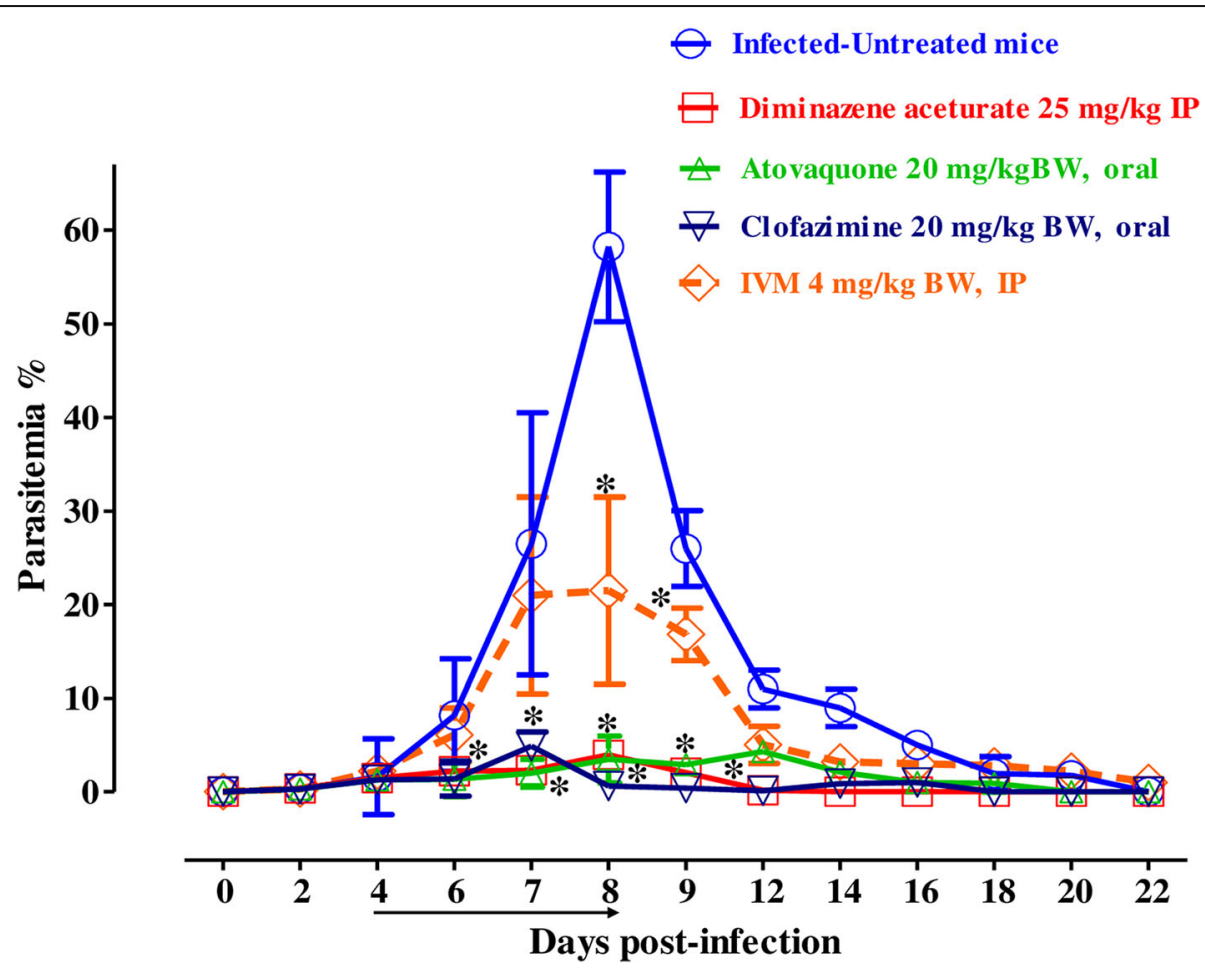

Fig. 3 The growth inhibition of IVM on B. microti in vivo. Graph showing the inhibitory effects of DA-IP, AQ-oral, CF-oral, IVM-IP treatment as compared to the untreated group. The values plotted indicate the mean \pm standard deviation for two separate experiments. Asterisks $\left(^{*}\right)$ indicate statistical significance $(p<0.05)$ based on one-way ANOVA Tukey's test using GraphPad Prism version 5.0 for Windows (GraphPad Software Inc., San Diego, CA, USA). The arrow indicates five consecutive days of treatment. Parasitemia was calculated by counting infected RBCs among 2000 RBCs using Giemsa-stained thin blood smears 


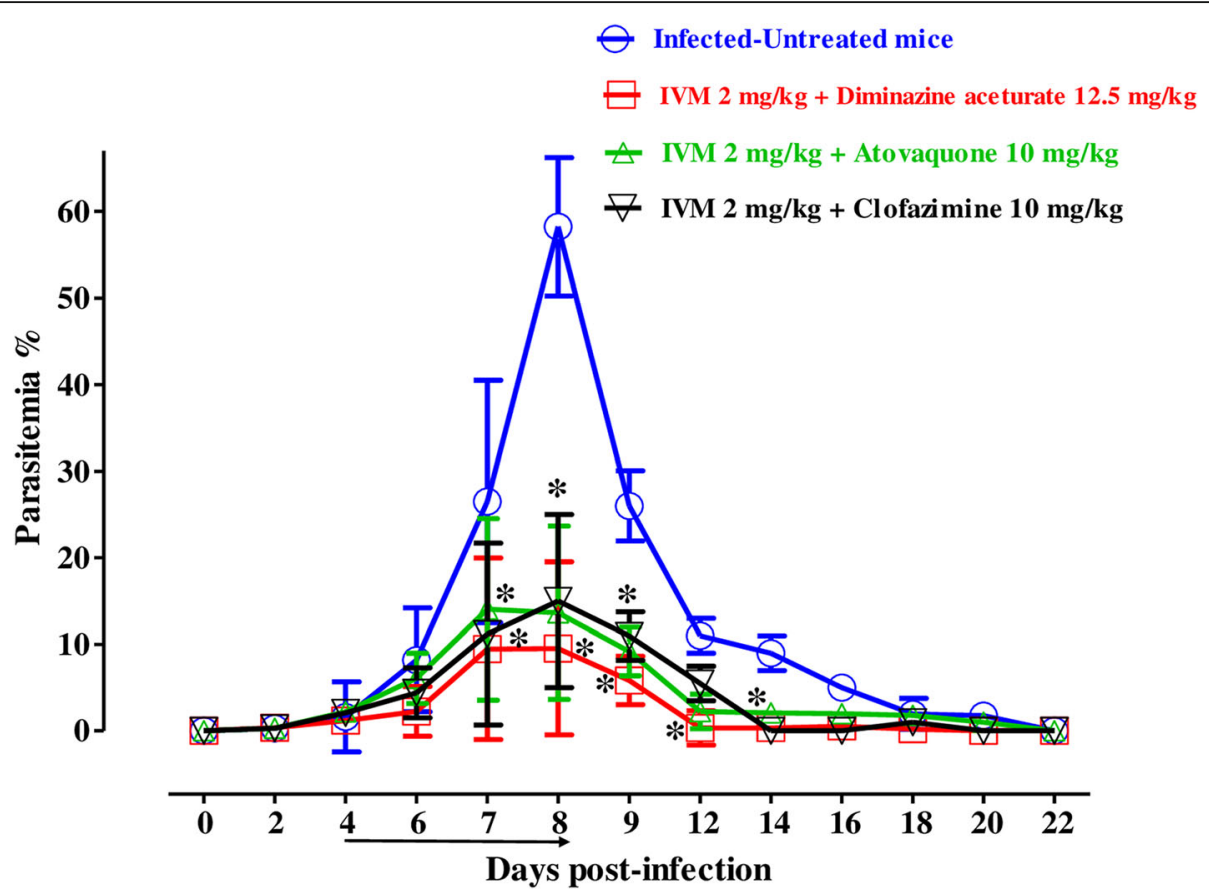

Fig. 4 The growth inhibition of IVM combinations on B. microti in vivo. The graph shows the inhibitory effects of $D A$, $A Q$, and $C F$ combined with IVM treatments as compared with the untreated group. The values plotted indicate the mean \pm standard deviation for two separate experiments. The asterisks $\left(^{*}\right)$ indicate statistical significance $(p<0.05)$ based on one-way ANOVA Tukey's test using GraphPad Prism version 5.0 for Windows (GraphPad Software Inc., San Diego, CA, USA). The arrow indicates five consecutive days of treatment. Parasitemia was calculated by counting infected RBCs among 2000 RBCs using Giemsa-stained thin blood smears

and equine Babesia/Theileria parasites [23], and metronidazole and clindamycin phosphate against $B$. gibsoni [24]. Interestingly, several reports documented the effectiveness of IVM on Plasmodium which is one of the apicomplexan parasites closely related to Babesia and Theileria [25], and on Leishmania, and Trypanosoma parasites $[15,16]$. This emphasizes that IVM is effective against many protozoan parasites.

Cytotoxicity studies showed that IVM was more likely to affect Babesia and Theileria than the host cells. This finding was consistent with that of Dou et al., who showed that IVM decreased the viability of breast cancer cell lines in a dose-dependent manner without cytotoxic activities on host cells [26].

Strikingly, the viability assay showed that IVM was more effective against Babesia than against Theileria parasites. B. bovis, $B$. divergens, $B$. bigemina, and $B$. caballi could not regrow with $4 \times \mathrm{IC}_{50}$ treatments of IVM, while $T$. equi could regrow at $4 \times \mathrm{IC}_{50}$ of IVM. This indicates that $T$. equi has better coping mechanisms to IVM treatment than Babesia parasites do. This finding is compatible with Reece et al., who reported that different malaria parasites species have used different coping mechanisms by changing in their investment in gametocytes during infections depending on their environment [27]. However, these patterns seem confusing; they can explain how parasites can respond to changes happened during infection. Therefore, T. equi might act by a different mechanism of action than that for Babesia species for coping the stress caused by IVM treatment. That may be one of the explanations of how can T. equi can be recovered again after the withdrawal of the drug pressure on the fourth day. However, we are unable to reach a definitive conclusion, since this study did not confirm the mode of action of IVM against Babesia and Theileria parasites. This finding is consistent with that of Tayebwa et al., who explained that $T$. equi might be affected through a different pathway than that for Babesia species [28].

Interestingly, combination chemotherapy has been recommended against drug-resistant protozoal and bacterial pathogens. Since, IVM is a well-known antiparasitic drug with a broad spectrum of activity, high efficacy, and it is used widely in the veterinary and human medicine $[11,12]$. Additionally, the inhibition and cytotoxicity assays in the current study revealed that IVM showed higher $\mathrm{IC}_{50}$ values and lower selective index than currently available antibabesial drugs (DA, AQ, and $\mathrm{CF}$ ). Therefore, the combination study aimed to enhance the potency of IVM while reducing the dose that led to reduced toxicity, subsequently reducing their toxic side effects. The in vitro combination treatment of IVM with 


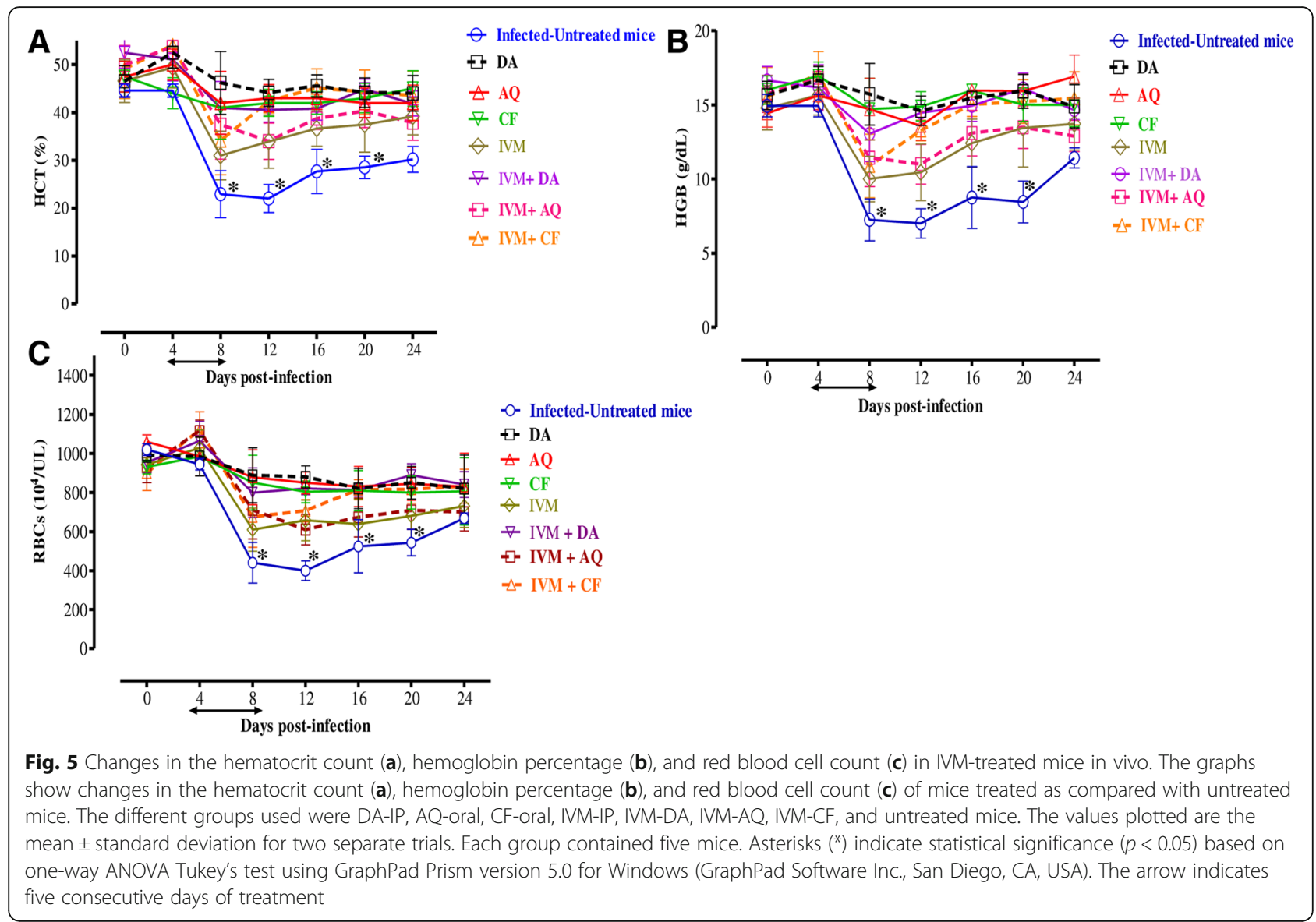

DA, AQ, or CF revealed synergistic and additive effects against Babesia and Theileria parasites. Whereas, in the combination chemotherapy, drugs that share the same mode of action tend to yield a synergistic effect, which can be defined as the greater effect of two drugs in the combination than the sum of each drug when acting separately, or an additive effect, in which two drugs in the combination produce an effect equal to the sum of each drug when acting separately. Therefore, there is a need for further studies to reveal the exact mechanism of action of IVM against Babesia and Theileria and then, clarify the reason behind this synergetic and additive effect of the combined treatment with $\mathrm{DA}, \mathrm{AQ}$, and $\mathrm{CF}$ and choose the best combination to be used in the field.

The promising efficacy of IVM in vitro prompted us to evaluate its performance in vivo. IVM administered

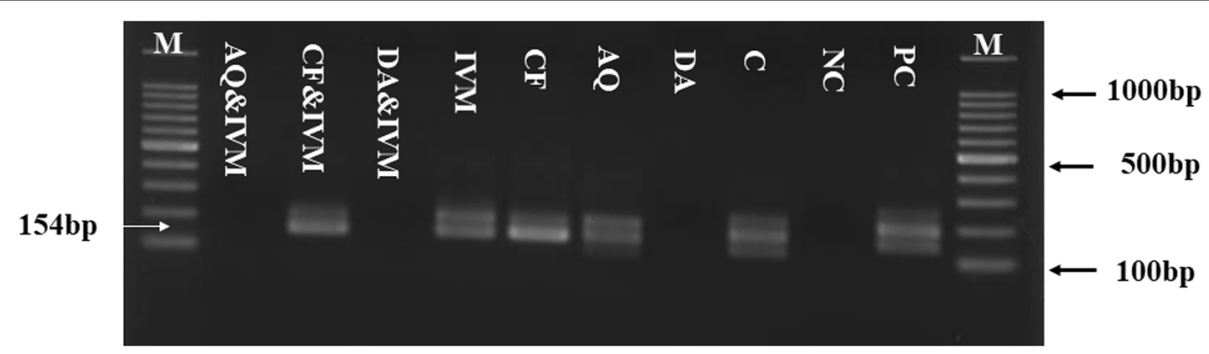

Fig. 6 Molecular detection of parasite DNA in the treated groups. The image shows the molecular detection of parasites in the blood of treated groups on day 49. $\mathrm{M}$ is for the marker, $\mathrm{NC}$ is for the untreated-uninfected group that was used as a negative control, PC is for the untreatedinfected group which used as the positive control, and C is for B. microti DNA control. The arrow shows the expected band length of 154 bp for positive cases of $B$. microti. The double bands observed with some of the positive controls represent amplicons of the first and second PCR. While a single band was observed in other groups due to the lower parasite DNA concentration 
intraperitoneally resulted in an inhibitory effect in vivo but at lower rates than those with $\mathrm{DA}, \mathrm{AQ}$, and CF. IVM-DA, IVM-AQ, and IVM-CF combinations were evaluated in mice to determine whether combination treatment would reduce the dose needed of the single drugs without altering their therapeutic efficacy against B. microti infection. Interestingly, our results are compatible with Mendes et al., who revealed that oral administration of IVM at a concentration of $10 \mathrm{mg} / \mathrm{kg}$ resulted in $80 \%$ inhibition of Plasmodium berghei in vivo [29]. Additionally, Taman et al. documented that oral administration of IVM at a concentration of $25 \mathrm{mg} / \mathrm{kg}$ resulted in a significant reduction in Schistosoma mansoni female worms. While, administration of the same dose for two consecutive days revealed reduction of $45.4 \%$, $27.6 \%$, and $28.8 \%$ in female, male worms, and total worm burdens, respectively when compared to infected control groups receiving the vehicle only. Additionally, IVM showed higher chemotherapeutic effect than a high dose of praziquantel (six times higher dose than IVM), which is the reference drug used for the treatment of schistosomiasis [30]. Combination treatment of IVMDA, IVM-AQ, and IVM-CF at half doses improved the efficacy of IVM at higher rates than those of monotherapy. The potentiation of IVM that was achieved in in vivo combination therapy confirmed the result that was observed in vitro, which draws attention to IVM as a good combinative drug. This finding is consistent with Canton et al., who reported ivermectin (IVM) and ricobendazole (RBZ) combination obtained significantly higher efficacy against IVM-resistant Haemonchus spp. than IVM and RBZ alone which have been proposed as a valid strategy to achieve effective nematode control in the presence of drug resistance [31].

In order to confirm the ability of IVM to eliminate $B$. microti, a PCR assay was performed on samples collected on day 49 p.i. Interestingly, this study confirmed the absence of $B$. microti DNA in groups treated with combination chemotherapy of IVM-DA and IVM-AQ. These results confirmed the importance of combination chemotherapy in the effective control of piroplasmosis. This finding further compels the need for combination therapy to achieve optimal efficacy and prevent relapse of infection or the development of a carrier state [32, 33]. Complimentarily, and consistent with a previous study (Udensi and Fagbenro-Beyioku), IVM did not show toxic side effects in mice [15]. Taken together, the findings advocate that IVM is a potential drug against human babesiosis as well as bovine and equine piroplasmosis. Even though IVM showed slightly low selective index, its combination with DA, $A Q$, and $C F$ at lower concentrations than the single drugs could improve its effect and subsequently reduce its toxicity [32, 33].

\section{Conclusion}

IVM showed efficacies on Babesia and Theileria consistent with efficacies reported on P. falciparum, Leishmania, and Trypanosoma. IVM effectiveness in vivo was comparable to that showed by DA and showed no toxic signs in mice. Therefore, IVM could be used as a chemotherapeutic drug for piroplasmosis. However, further studies are required to detect the exact mechanism of action of IVM on Babesia and Theileria parasites.

\section{Methods \\ Cultivation conditions \\ Parasites and mice}

The United States Department of Agriculture (USDA) strain of $T$. equi and $B$. caballi, the German bovine strain of $B$. divergens [32], the Texas strain of B. bovis, and the Argentina strain of $B$. bigemina were used for the in vitro studies [28]; for the in vivo studies, $B$. microti (Munich strain) was used [28, 34]. Eight-weekold female BALB/c mice (CLEA Japan, Inc., Tokyo, Japan) were housed in a pathogen-free environment with controlled temperature $\left(22{ }^{\circ} \mathrm{C}\right)$, humidity, and a $12 \mathrm{~h}$ light/dark cycle, and used for cultivation of $B$. microti for in vivo studies.

\section{Chemicals and reagents}

Ivermectin (IVM), diminazene aceturate (DA), atovaquone (AQ), and clofazimine (CF) (Sigma-Aldrich, Japan) were prepared in dimethyl sulfoxide (DMSO) in stock solutions of $10 \mathrm{mM}$ and stored at $-30{ }^{\circ} \mathrm{C}$. A lysis buffer containing Tris- $\mathrm{HCl}(130 \mathrm{mM}$ at $\mathrm{pH} 7.5)$, EDTA $(10 \mathrm{mM})$, saponin $(0.016 \% \mathrm{w} / \mathrm{v})$, and Triton $\mathrm{X}-100(1.6 \%$ $v / v)$ was prepared, filtered through $0.22 \mu \mathrm{m}$ of polyether sulfone, and stored at $4{ }^{\circ} \mathrm{C}$ to be mixed with $10,000 \times$ SYBR Green I (SGI) nucleic acid stain (Lonza, USA) $0.2 \mu \mathrm{L} / \mathrm{mL}$ before measuring the fluorescence.

\section{In vitro cultivation of parasites}

Purified equine or bovine red blood cells (RBCs) were used to maintain B. caballi, T. equi, B. bovis, B. bigemina, and $B$. divergens. A microaerophilic stationaryphase culture system at $37{ }^{\circ} \mathrm{C}, 5 \% \mathrm{CO}_{2}, 5 \% \mathrm{O}_{2}$, and $90 \%$ $\mathrm{N}_{2}$ was used for the parasite cultivation as previously described [32]. For B. bigemina and B. bovis culture, medium 199 (M199; Sigma-Aldrich, Tokyo, Japan), supplemented with $40 \%$ bovine serum, was used for cultivation, while medium RPMI 1640 (Sigma-Aldrich, Tokyo, Japan) supplemented with $40 \%$ bovine serum was used to culture B. divergens. GIT (Sigma-Aldrich, Tokyo, Japan) supplemented with $40 \%$ equine serum was used to maintain B. caballi culture, while M199 supplemented with $40 \%$ equine serum and $13.6 \mu \mathrm{g} / \mathrm{mL}$ of hypoxanthine was used for $T$. equi cultivation. Further, $60 \mu \mathrm{g} / \mathrm{mL}$ of streptomycin and $0.15 \mu \mathrm{g} / \mathrm{mL}$ of amphotericin $\mathrm{B}$ were 
added to all of the culture media to prevent bacterial and fungal contamination. In vitro cultures of all five parasites were subcultured every 4 or 5 days to maintain good parasite growth.

\section{Cell cultures}

Human foreskin fibroblast (HFF), Madin-Darby bovine kidney (MDBK) cell lines, and mouse embryonic fibroblasts (NIH/3 T3) were maintained in $75 \mathrm{~cm}^{2}$ culture flasks and incubated continuously at $37{ }^{\circ} \mathrm{C}$ in a humidified incubator with $5 \% \mathrm{CO}_{2}$. Minimum Essential Medium Eagle (MEM; Gibco, Life Technologies, Grand Island, NY, USA) was used for MDBK cell cultivation, while Dulbecco's modified Eagle's medium (DMEM; Gibco, Life Technologies, Grand Island, NY, USA) was used for NIH/3 T3 and HFF cell cultivation. Each medium was supplemented with $10 \%$ fetal bovine serum, $50 \mu \mathrm{g} / \mathrm{mL}$ penicillin/streptomycin (Gibco, Life Technologies, Grand Island, NY, USA), and an additional $2 \mathrm{mM}$ glutamine. The medium was changed every 3 to 4 days and incubated until approximately $80 \%$ confluent. The cells were stained with 4,6-diamidino-2-phenylindole dihydrochloride (DAPI; SigmaAldrich, St. Louis, MO, USA) to check mycoplasma-free contamination. After that, the cells were washed two times with Dulbecco's phosphate-buffered saline (DPBS), and TrypLE Express (Gibco, Life Technologies, Grand Island, NY, USA) was used to allow cell detachment. Subsequently, viable cells were counted using a Neubauer improved C-Chip (NanoEn Tek Inc., Seoul, Korea) after staining with $0.4 \%$ Trypan blue solution.

\section{Cytotoxicity assay of IVM on HFF, MDBK, and NIH/3 T3 cell lines}

The drug-exposure viability assay was performed in accordance with the protocol described previously [32]. Briefly, $100 \mu \mathrm{L}$ of cells at a density of $5 \times 10^{4}$ cells $/ \mathrm{mL}$ was seeded per well and allowed to attach to a 96-well plate for $24 \mathrm{~h}$ at $37{ }^{\circ} \mathrm{C}$ in a humidified incubator with $5 \% \mathrm{CO}_{2}$. For IVM, $10 \mu \mathrm{L}$ of twofold dilutions was added to each well to a final concentration of $12.5 \mu \mathrm{M}$ to $500 \mu \mathrm{M}$ in triplicate, while for $\mathrm{DA}, \mathrm{AQ}$, and CF, $10 \mu \mathrm{L}$ of twofold dilutions was added to each well, to a final concentration of $100 \mu \mathrm{M}$ in triplicate. Wells with only a culture medium were used as blanks, while wells containing cells and a medium with $0.4 \%$ DMSO were used as a positive control. Subsequently, the plate was incubated for another $24 \mathrm{~h}$. Ten microliters of Cell Counting Kit-8 (CCK-8) was added, and the plate was further incubated for $3 \mathrm{~h}$; the absorbance was then measured at $450 \mathrm{~nm}$ using a microplate reader.

\section{The effects of IVM in host erythrocytes in vitro}

The effects of IVM on bovine and equine RBCs were measured in accordance with the protocol previously described [28]. Briefly, bovine and equine RBCs were incubated in the presence of 10,100 , and $200 \mu \mathrm{M}$ of IVM for 3 and $6 \mathrm{~h}$ at $37{ }^{\circ} \mathrm{C}$. Afterward, the erythrocytes were washed thrice with drug-free media and used for the cultivation of $B$. bovis, $B$. bigemina, $B$. divergens, $B$. caballi, and T. equi. The untreated RBCs were used as a control. The effect was monitored using the fluorescence assay.

\section{Growth inhibitory effects in vitro}

A fluorescent assay was used to determine the halfmaximal inhibitory concentration $\left(\mathrm{IC}_{50}\right)$ for IVM, DA, $\mathrm{AQ}$, and CF as previously described [28, 34]. Briefly, IVM and CF in quantities of $1.56,3.125,6.25,12.5,25$, 50, 100, 200, and $250 \mu \mathrm{M}$, as well as DA and AQ in quantities of $0.007,0.015,0.03,0.06,0.125,0.25,0.5$, and $1 \mu \mathrm{M}$, were placed in a 96-well plate in triplicate to determine inhibition concentrations, with a $2.5 \%$ hematocrit for B. bovis and B. bigemina and a $5 \%$ hematocrit for $B$. divergens, B. caballi, and T. equi. Wells containing infected red blood cells (iRBCs) were used as positive controls, while wells with non-infected red blood cells (RBCs) were used as negative controls. The plate was incubated at $37{ }^{\circ} \mathrm{C}$ in a humidified multi-gas water-jacketed incubator with an atmosphere of 5\% $\mathrm{CO}_{2}, 5 \% \mathrm{O}_{2}$, and $90 \% \mathrm{~N}_{2}$ for $96 \mathrm{~h}$ without changing media. After $96 \mathrm{~h}, 100 \mu \mathrm{L}$ of lysis buffer containing SGI was directly added to each well and mixed gently by pipetting, wrapped in aluminum foil for protection from direct light, and incubated for $6 \mathrm{~h}$ at room temperature. The plate was then placed into the fluorescence spectrophotometer (Fluoroskan Ascent, Thermo LabSystems, Oceanside, California, USA). Relative fluorescence values were read at 485 and $518 \mathrm{~nm}$ for excitation and emission wavelengths, respectively. Gain values were set to percentages after subtraction of the mean values of the negative control and transferred into GraphPad Prism (GraphPad Software Inc. San Diego, CA, USA) to calculate the $\mathrm{IC}_{50}$ value using the nonlinear regression analysis (curve fit).

\section{Viability experiment in vitro}

The assay was conducted in accordance with the protocol described previously [28]. Briefly, a $100 \mu \mathrm{L}$ reaction volume, containing $90 \mu \mathrm{L}$ of medium with different drug concentrations $\left(0.25 \times, 0.5 \times, 1 \times, 2 \times\right.$, and $4 \times$ the $\mathrm{IC}_{50}$ of IVM and DA) and $10 \mu \mathrm{L}$ of iRBCs adjusted to $1 \%$ parasitemia, was incubated in a 96-well microtiter plate at $37{ }^{\circ} \mathrm{C}$ in a humidified multi-gas water-jacketed incubator. The medium was changed daily for 4 days and replaced with new medium containing the same concentrations of drugs. In the course of treatment, Giemsa-stained thin blood smears were prepared, and the parasitemia was monitored every $12 \mathrm{~h}$ by counting the number of infected RBCs among 2000 RBCs. On day 
5, $3 \mu \mathrm{L}$ of treated RBCs from each well was mixed with $7 \mu \mathrm{L}$ of fresh RBCs, transferred into a new 96-well microtiter plate, and cultured in drug-free medium. The medium was replaced every day, and the viability of drug-treated parasites was checked in Giemsa-stained thin blood smears 6 days after the last treatment. Parasitemia was calculated. The presence of parasites was recorded as positive (relapse), while no parasite was recorded as negative (total parasite clearance). Each experiment was performed in triplicate in three separate trials.

\section{Combination treatment of IVM with $D A, A Q$, and CF in vitro}

The combination assay was conducted in accordance with the protocol previously described [32] in three separate trials. Three sets of duplicate wells with five selected concentrations, $0.25 \times, 0.5 \times, 1 \times, 2 \times$, and $4 \times$ the $\mathrm{IC}_{50}$ of IVM with $\mathrm{DA}, \mathrm{AQ}$, and $\mathrm{CF}$ were cultivated in a 96-well plate (Additional file 1: Table S1). IVM single treatments were added to the first set of wells, while the second set of wells contained various concentrations of $\mathrm{DA}, \mathrm{AQ}$, or CF single treatments, and the third set contained the combinations of IVM with DA, AQ, or CF $(\mathrm{IVM}+\mathrm{DA}, \mathrm{IVM}+\mathrm{AQ}, \mathrm{IVM}+\mathrm{CF})$ at a constant ratio (1:1) [18]. One hundred microliter reaction volumes of media containing the drug concentrations and $2.5 \%$ and $5 \%$ hematocrits for $B$. bovis and B. bigemina and $B$. divergens, B. caballi, and T. equi, respectively, were cultivated for 4 days in a humidified incubator with $5 \% \mathrm{CO}_{2}$, $5 \% \mathrm{O}_{2}$, and $90 \% \mathrm{~N}_{2}$. On day $4,100 \mu \mathrm{L}$ of lysis buffer containing $2 \times \mathrm{SG} 1$ was added, and the plate was wrapped with aluminum foil for protection from light and incubated for $6 \mathrm{~h}$ at room temperature. Afterward, the plate was loaded into a fluorescence spectrophotometer, and the relative fluorescence values were read at 485 and $518 \mathrm{~nm}$ for excitation and emission wavelengths, respectively. The obtained fluorescence values were set to percentages after subtracting the mean values of the negative control. The growth inhibition values obtained were entered into Compusyn software for calculating the degree of association based on the combination index $(\mathrm{CI})$ values. The $\mathrm{CI}$ values of the drug combination were determined using the formula $[(1 \times$ $\left.\left.\mathrm{IC}_{50}\right)+\left(2 \times \mathrm{IC}_{75}\right)+\left(3 \times \mathrm{IC}_{90}\right)+\left(4 \times \mathrm{IC}_{95}\right)\right] / 10$ (Additional file 2: Table S2), and the results were described as synergistic, additive, or antagonistic in accordance with the combination index scale: $<0.90,0.90-1.10$, and $>1.10$, respectively [18].

\section{Chemotherapeutic effects of IVM against B. microti}

The in vivo inhibitory effects of IVM were evaluated against B. microti in mice as previously described [28]. Briefly, B. microti recovered from frozen stock (stored at $-80{ }^{\circ} \mathrm{C}$ ) was thawed and injected into two mice intraperitoneally. The parasitemia was monitored every day by microscopy, and when the parasitemia was over $30 \%$, the mice were sacrificed, and blood was collected by cardiac puncture. After that, phosphate-buffered saline was used to dilute the blood to obtain an inoculum containing $1 \times 10^{7} / \mathrm{mL}$ of B. microti iRBCs. Forty-five female 8-week-old BALB/c mice were caged in nine groups. The mice in group 1 were left uninfected to act as the negative control, while groups 2-9 were injected intraperitoneally (i.p.) with $0.5 \mathrm{~mL}$ of inoculum $\left(1 \times 10^{7}\right.$ B. microti iRBCs). When the average parasitemia in all mice reached $1 \%$, drug treatment was initiated for 5 days. The mice in group 2 were administered $0.2 \mathrm{~mL}$ of DDW intraperitoneally to act as the positive control, while groups 3 and 4 were i.p. injected with $0.2 \mathrm{~mL}$ of $25 \mathrm{mg} /$ $\mathrm{kg}$ DA and $4 \mathrm{mg} / \mathrm{kg}$ of IVM single treatment, respectively. Groups 5 and 6 received $0.2 \mathrm{~mL} 20 \mathrm{mg} / \mathrm{kg} \mathrm{AQ}$ and $20 \mathrm{mg} / \mathrm{kg}$ CF single treatment orally, respectively. Groups 7-9 were treated with combinations of IVM $+\mathrm{DA}, \mathrm{IVM}+\mathrm{AQ}$, and IVM + CF, respectively. The parasitemia and hematocrit were monitored every 2 and 4 days for 45 days by microscopy and a hematology analyzer (Celltac a MEK-6450, Nihon Kohden Corporation, Tokyo, Japan), respectively. On day 49, all mice were anesthetized, and the blood was collected by cardiac puncture for PCR detection of parasites. The experiment was conducted two times. The significant differences between groups were determined by independent Student's $t$ test and one-way ANOVA Tukey's test using GraphPad Prism version 5.0 for Windows (GraphPad Software Inc., San Diego, CA, USA). A $p$ value of $<0.05$ was considered statistically significant.

\section{Genomic DNA extraction and PCR detection of B. microti}

A nested PCR (nPCR) targeting the B. microti smallsubunit rRNA (ss-rRNA) gene was carried out in accordance with the previously described protocol $[28,35]$ after extracting the genomic DNA from the blood using a QIAamp DNA Blood Mini Kit (Qiagen, Tokyo, Japan). Briefly, a $10 \mu \mathrm{L}$ reaction mixture containing $0.5 \mu \mathrm{M}$ of each primer, $2 \mu \mathrm{L}$ of $5 \times$ SuperFi $^{\mathrm{im}}$ buffer, $0.2 \mathrm{mM} \mathrm{dNTP}$ mix, $0.1 \mu \mathrm{L}$ of Platinum SuperFi ${ }^{\mathrm{m}}$ DNA polymerase (Thermo Fisher Scientific, Tokyo, Japan), $1 \mu \mathrm{L}$ of DNA template, and $4.9 \mu \mathrm{L}$ of DDW was used to conduct the PCR amplification. The cycling conditions were $94{ }^{\circ} \mathrm{C}$, $53{ }^{\circ} \mathrm{C}$, and $72{ }^{\circ} \mathrm{C}$ for $30 \mathrm{~s}$ as denaturation, annealing, and extension steps for 35 cycles using the forward $\left(5^{\prime}\right.$-CTTA GTATAAGCTTTTATACAGC-3') and reverse primer (5' -ATAGGTCAGAAACTTGAATGATACA-3'). Subsequently, under similar cycling conditions, $1 \mu \mathrm{L}$ of DNA template from the first PCR amplification was used as the template for the nPCR assay using the forward ( $5^{\prime}$-GTTATAGTTTATTTGATGTTCGTTT-3') and reverse primers 
(5'-AAGCCATGCGATTCGCTAAT-3'). The PCR products were then resolved by electrophoresis in a $1.5 \%$ agarose gel, stained with ethidium bromide, and visualized under the UV transilluminator. The bands with an expected size of $154 \mathrm{bp}$ were considered positive.

\section{Statistical analysis}

The $\mathrm{IC}_{50}$ values of IVM, DA, AQ, and CF were determined using the nonlinear regression curve fit in GraphPad Prism (GraphPad Software Inc., San Diego, CA, USA). Differences in parasitemia, hematology profiles, and body weight were analyzed using an independent Student's $t$ test and one-way ANOVA Tukey's test using GraphPad Prism version 5.0 for Windows (GraphPad Software Inc., San Diego, CA, USA). A $p$ value $<0.05$ was considered statistically significant.

\section{Ethical clearance}

All experiments were approved by the Animal Welfare Committee and performed in accordance with standards for the care and management of experimental animals as stipulated by Obihiro University of Agriculture and Veterinary Medicine (accession number of the animal experiment: $28-111-2 / 28-110)$.

\section{Additional files}

Additional file 1: Table S1. Concentrations of ivermectin combined with diminazene aceturate and atovaquone against Babesia and Theileria parasites in vitro (DOCX $21 \mathrm{~kb})$

Additional file 2: Table S2. Calculation of weighted average of combination Index values (DOCX $17 \mathrm{~kb}$ )

Additional file 3: Table S3. The $I_{50}$ and selectivity index of $D A, A Q$, and CF (DOCX $19 \mathrm{~kb})$

\section{Abbreviations}

AQ: Atovaquone; BW: Body weight; CF: Clofazimine; DA: Diminazene aceturate; $\mathrm{EC}_{50}$ : Half-maximal effective concentration; HCT: Hematocrit; HFF: Human foreskin fibroblast; HGB: Hemoglobin; IC 50 : Half-maximal inhibitory concentration; IP: Intraperitoneally; IVM: Ivermectin; MDBK: MadinDarby bovine kidney; NIH/3 T3: Mouse embryonic fibroblast; PCR: Polymerase chain reaction; $\mathrm{RBC}$ : Red blood cells; RBZ: Ricobendazole

\section{Acknowledgments}

Not applicable.

\section{Funding}

This study was supported by the Japan Society for the Promotion of Science (JSPS) KAKEN, Grant Number 18 H02337.

\section{Availability of data and materials}

Raw data are available from the corresponding author on reasonable request.

\section{Authors' contributions}

GEB and AM screening, analyzed and interpreted the data, and drafted the manuscript with the help of OA, DT, and NY and II were major contributors to the writing of the manuscript. GEB, AM, DT, NY, and II contributed to the conception of the study. All authors read and approved the final manuscript.

\section{Ethics approval and consent to participate}

This study was approved by the Animal Welfare Committee and performed in accordance with standards for the care and management of experimental animals as stipulated by Obihiro University of Agriculture and Veterinary Medicine (accession number of the animal experiment: 28-111-2/28-110).

Consent for publication

Not applicable.

\section{Competing interests}

The authors declare that they have no competing interests.

\section{Publisher's note}

Springer Nature remains neutral with regard to jurisdictional claims in published maps and institutional affiliations.

\section{Author details}

${ }^{1}$ National Research Center for Protozoan Diseases, Obihiro University of Agriculture and Veterinary Medicine, Nishi 2 Sen-13, Inada-cho, Obihiro, Hokkaido 080-8555, Japan. ${ }^{2}$ Department of Pharmacology and Therapeutics, Faculty of Veterinary Medicine, Damanhour University, Damanhour, El Beheira 22511, Egypt. ${ }^{3}$ Research Center for Tick and Tick-Borne Diseases, College of Veterinary Medicine, Animal Resources and Biosecurity, Makerere University, PO Box 7062, Kampala, Uganda. ${ }^{4}$ Medicinal Biochemistry, Nanomedicine and Toxicology Laboratory, Department of Biological Sciences, Landmark University, Omu-Aran, Kwara 251101, Nigeria.

Received: 6 February 2019 Accepted: 24 June 2019

Published online: 11 July 2019

\section{References}

1. Hamoda AF, Radwan M, Rashed R, Amin A. Toxic effect of babesiosis in cattle and chemotherapiotic treatment in Egypt. Am J Infect Dis Microbiol. 2014;2:91-6. https://doi.org/10.12691/ajidm-2-5-1

2. Zintl A, Mulcahy G, Skerrett HE, Taylor SM, Gray JS. Babesia divergens, a bovine blood parasite of veterinary and zoonotic importance. Clin Microbiol Rev. 2003;16:622-36. https://doi.org/10.1128/CMR.16.4.622-636.2003. https:// doi.org/10.1128/CMR.16.4.622-636.2003.

3. Wise LN, Pelzel-McCluskey AM, Mealey RH, Knowles DP. Equine piroplasmosis. Vet Clin North Am Equine Pract. 2014;30:677-93. https://doi. org/10.1016/j.cveq.2014.08.008.

4. Krause PJ, McKay K, Gadbaw J, Christianson D, Closter L, Lepore T, et al. Increasing health burden of human babesiosis in endemic sites. Am J Trop Med Hyg. 2003;68:431-6. https://doi.org/10.4269/ajtmh.2003.68.431.

5. De Vos AJ, Bock RE. Vaccination against bovine babesiosis. Ann N Y Acad Sci 2006;916:540-545. https://doi.org/10.1111/j.1749-6632.2000.tb05333.x.

6. Vannier E, Gewurz BE, Krause PJ. Human babesiosis. Infect Dis Clin N Am. 2008:22:469-88. https://doi.org/10.1016/j.idc.2008.03.010. https://doi. org/10.1016/j.idc.2008.03.010.

7. Gonzalez LM, Rojo S, Gonzalez-Camacho F, Luque D, Lobo CA, Montero E. Severe babesiosis in immunocompetent man, Spain, 2011. Emerg Infect Dis. 2014;20:724-6. https://doi.org/10.3201/eid2004.131409. https:// doi.org/10.3201/eid2004.131409.

8. Hatcher JC, Greenberg PD, Antique J, Jimenez-Lucho VE. Severe babesiosis in Long Island: review of 34 cases and their complications. Clin Infect Dis. 2001; 32:1117-25. https://doi.org/10.1086/319742. https://doi.org/10.1086/319742.

9. Matsuu A, Miyamoto K, Ikadai H, Okano S, Higuchi S. Short report: cloning of the Babesia gibsoni cytochrome B gene and isolation of three single nucleotide polymorphisms from parasites present after atovaquone treatment. Am J Trop Med. 2006;74:593-7.

10. Jin $L$, Feng $X$, Rong $H$, Pan Z, Inaba $Y$, Qiu L, et al. The antiparasitic drug ivermectin is a novel FXR ligand that regulates metabolism. Nat Commun. 2013;4(1937) https://doi.org/10.1038/ncomms2924

11. Fisher $\mathrm{MH}$, Mrozik $\mathrm{H}$. The chemistry and pharmacology of avermectins. Annu Rev Pharmacol Toxicol. 1992;32:537-53. https://doi.org/10.1146/ annurev.pa.32.040192.002541.

12. Pinilla YT, Lopes SCP, Sampaio VS, Andrade FS, Melo GC, Orfanó AS, et al. Promising approach to reducing malaria transmission by ivermectin: sporontocidal effect against Plasmodium vivax in the south American vectors Anopheles aquasalis and Anopheles darlingi. PLoS Negl Trop Dis. 2018;12:e0006221. https://doi.org/10.1371/journal.pntd.0006221. 
13. Brooks P, Grace R. Ivermectin is better than benzyl benzoate for childhood scabies in developing countries. J Paediatr Child Health. 2002;38:401-4. https://doi.org/10.1046/j.1440-1754.2002.00015.x.

14. Omura S, Crump A. Ivermectin: panacea for resource-poor communities? Trends Parasitol. 2014;30:445-55.

15. Udensi UK, Fagbenro-Beyioku AF. Effect of ivermectin on Trypanosoma brucei brucei in experimentally infected mice. J Vector Borne Dis. 2012;49:143-50.

16. Rasheid KA, Morsy TA. Efficacy of ivermectin on the infectivity of Leishmania major promastigotes. J Egypt Soc Parasitol. 1998;28:207-12.

17. Ōmura S, Crump A. Ivermectin and malaria control. Malar J. 2017;16:172. https://doi.org/10.1186/s12936-017-1825-9

18. Chou T-C. Theoretical basis, experimental design, and computerized simulation of synergism and antagonism in drug combination studies. Pharmacol Rev. 2006;58:621-81. https://doi.org/10.1124/pr.58.3.10.

19. El Bahy NM, Bazh EK, Shaheen HM. Efficacy of deltamethrin, diazinon, and ivermectin on Boophilus annulatus ticks (in vitro and in vivo study). Parasitol Res. 2015;114:29-36. https://doi.org/10.1007/s00436-014-4129-9.

20. Morsy TA, Haridy FM. Effect of ivermectin on the brown dog tick, Rhipicephalus sanguineus. J Egypt Soc Parasitol. 2000;30:117-24.

21. Rizk MA, El-Sayed SAE, AbouLaila M, Yokoyama N, Igarashi I. Evaluation of the inhibitory effect of $\mathrm{N}$-acetyl-L-cysteine on Babesia and Theileria parasites. Exp Parasitol. 2017;179:43-8. https://doi.org/10.1016/j.exppara.2017.06.003.

22. Salama AA, AbouLaila M, Terkawi MA, Mousa A, El-Sify A, Allaam M, et al. Inhibitory effect of allicin on the growth of Babesia and Theileria equi parasites. Parasitol Res. 2014;113:275-83. https://doi.org/10.1007/s00436-013-3654-2.

23. Bork S, Yokoyama N, Matsuo T, Claveria FG, Fujisaki K, Igarashi I. Clotrimazole, ketoconazole, and clodinafop-propargyl inhibit the in vitro growth of Babesia bigemina and Babesia bovis (phylum Apicomplexa). Parasitol. 2003;127:311-5. https://doi.org/10.1017/S0031182003003895.

24. Matsuu A, Yamasaki M, Xuan X, Ikadai H, Hikasa Y. In vitro evaluation of the growth inhibitory activities of 15 drugs against Babesia gibsoni (Aomori strain). Vet Parasitol. 2008;157:1-8. https://doi.org/10.1016/j.vetpar.2008.07.023.

25. Panchal M, Rawat K, Kumar G, Kibria KM, Singh S, Kalamuddin M, et al. Plasmodium falciparum signal recognition particle components and antiparasitic effect of ivermectin in blocking nucleo-cytoplasmic shuttling of SRP. Cell Death Dis. 2014;5:e994. https://doi.org/10.1038/cddis.2013.521. https://doi.org/10.1038/cddis.2013.521.

26. Dou Q, Chen H-N, Wang K, Yuan K, Lei Y, Li K, et al. Therapeutics, targets, and chemical biology: ivermectin induces cytostatic autophagy by blocking the PAK1/Akt Axis in breast cancer. Cancer Res. 2016;76:4457-69. https://doi. org/10.1158/0008-5472.CAN-15-2887

27. Reece SE, Ramiro RS, Nussey DH. Plastic parasites: sophisticated strategies for survival and reproduction? Evol Appl. 2009;2:11-23. https://doi.org/10. 1111/j.1752-4571.2008.00060.x.

28. Tayebwa DS, Tuvshintulga B, Guswanto A, Nugraha AB, Batiha GE-S, Gantuya S, et al. The effects of nitidine chloride and camptothecin on the growth of Babesia and Theileria parasites. Ticks Tick Borne Dis. 2018;9:1192201. https://doi.org/10.1016/J.TTBDIS.2018.04.019. https://doi.org/10.1016/j. ttbdis.2018.04.019.

29. Mendes AM, Albuquerque IS, Machado M, Pissarra J, Meireles P, Prudêncio M. Inhibition of Plasmodium liver infection by ivermectin. Antimicrob Agents Chemother. 2017;61:e02005-16.

30. Taman A, El-Beshbishi S, El Tantawy N, El-Hawary A, Azab M. Evaluation of the in vivo effect of ivermectin on Schistosoma mansoni in experimentallyinfected mice. J Coast Life Med. 2014;2:817-23.

31. Canton C, Ceballos L, Fiel C, Moreno L, Domingo Yagüez P, Bernat G, et al. Resistant nematodes in cattle: pharmaco-therapeutic assessment of the ivermectin- ricobendazole combination. Vet Parasitol 2017;234:40-48, DOI: 10.1016/j.vetpar.2016.12.021.

32. Guswanto A, Nugraha AB, Tuvshintulga B, Tayebwa DS, Rizk MA, GE-S B, et al. 17-DMAG inhibits the multiplication of several Babesia species and Theileria equi on in vitro cultures, and Babesia microti in mice. Int J Parasitol Drugs Drug Resist. 2018;8:104-11. https://doi.org/10.1016/j.jpddr.2018.02.005.

33. Tuvshintulga B, AbouLaila M, Davaasuren B, Ishiyama A, Sivakumar T, Yokoyama N, et al. Clofazimine inhibits the growth of Babesia and Theileria parasites in vitro and in vivo. Antimicrob Agents Chemother. 2016;60:2739-46. https://doi.org/10.1128/AAC.0161415. https://doi.org/10.1128/AAC.01614-15.
34. Guswanto A, Sivakumar T, Rizk MA, Elsayed SAE, Youssef MA, ElSaid EES, et al. Evaluation of a fluorescence-based method for antibabesial drug screening. Antimicrob Agents Chemother. 2014;58:4713-7. https://doi.org/ 10.1128/AAC.00022-14.

35. Persing DH, Mathiesen D, Marshall WF, Telford SR, Spielman A, Thomford JW, et al. Detection of Babesia microti by polymerase chain reaction. J Clin Microbiol. 1992;30:2097-103.

\section{Ready to submit your research? Choose BMC and benefit from:}

- fast, convenient online submission

- thorough peer review by experienced researchers in your field

- rapid publication on acceptance

- support for research data, including large and complex data types

- gold Open Access which fosters wider collaboration and increased citations

- maximum visibility for your research: over $100 \mathrm{M}$ website views per year

At BMC, research is always in progress.

Learn more biomedcentral.com/submissions 